\title{
Efeitos do Sombreamento na Composição Mineral de Gramíneas Forrageiras Tropicais ${ }^{1}$
}

\author{
Carlos Renato Tavares de Castro², Rasmo Garcia ${ }^{3}$, Margarida Mesquita Carvalho ${ }^{4}$, \\ Vicente de Paula Freitas ${ }^{5}$
}

\begin{abstract}
RESUMO - Estudou-se a influência de três níveis de sombreamento artificial $(0,30$ e $60 \%)$ sobre a composição mineral de seis espécies de gramíneas forrageiras tropicais (Andropogon gayanus, Brachiaria brizantha, B. decumbens, Melinis minutiflora, Panicum maximum e Setaria sphacelata). O solo predominante na região foi classificado como Latossolo Vermelho-Amarelo de textura média e o ensaio foi conduzido segundo o delineamento em blocos ao acaso, com parcelas subdivididas, em quatro repetições; nas parcelas foram distribuídos os níveis de sombreamento e nas subparcelas, as espécies forrageiras. Constatou-se que, com o sombreamento, houve tendência geral à elevação dos teores de fósforo, potássio, cálcio e magnésio na forragem.
\end{abstract}

Palavras-chave: composição mineral, gramíneas, sombreamento artificial

\section{Effects of Shading in the Mineral Composition of Tropical Forage Grasses}

\begin{abstract}
The influence of three levels of artificial shade (0, 30 e 60\%) on mineral composition of six forage grasses (Andropogon gayanus, Brachiaria brizantha, B. decumbens, Melinis minutiflora, Panicum maximum and Setaria sphacelata) was studied. The predominant soil in the region was classified as red-yellow latosol of medium texture and the assay was conducted according to randomized block design, with split plots, in four replicates; the plots corresponded to the shading levels and the split plots corresponded to the forage species. Shading affected the mineral composition of grasses and there was a tendency of increasing the concentration of $\mathrm{P}, \mathrm{K}, \mathrm{Ca}$ and $\mathrm{Mg}$.
\end{abstract}

Key Words: artificial shading, grasses, mineral composition

\section{Introdução}

O interesse pelo estabelecimento de forrageiras à sombra tem crescido nos últimos anos, devido, principalmente, ao desejo de se associarem pastagens com árvores (WONG e WILSON, 1980), constituindo os sistemas silvipastoris, cujo sucesso depende da identificação de espécies tolerantes ao sombreamento e de práticas de manejo que assegurem a sua produtividade e persistência no sub-bosque (TORRES, 1982; WONG e STÜR, 1993).

Entretanto, as informações disponíveis quanto ao efeito do sombreamento na composição mineral de forrageiras referem-se a reduzido número de espécies. Vários ensaios com sombreamento natural, pelo estrato arbóreo, ou artificial, por meio de telas, foram conduzidos com espécies de clima temperado, obtendo-se resultados freqüentemente conflitantes; os trabalhos com espécies de clima tropical, além de serem em menor número, apresentam, muitas vezes, conclusões igualmente contrastantes.
Segundo CLARK (1981), a luz não atua diretamente na absorção de elementos minerais pelas plantas, porém afeta processos biológicos passíveis de alterar a sua composição mineral, como a fotossíntese, transpiração e respiração, entre outros.

A luz fornece energia para a absorção e metabolização dos nutrientes minerais (SMITH, 1968; RAVEN, 1969); sem energia tais processos não ocorrem, uma vez que a maioria das células vegetais acumula íons contra um gradiente de concentração (CLARK, 1981). A absorção da maioria dos nutrientes minerais é adequada e relativamente constante, quando há suficiente provisão de energia, porém, sob déficit energético, a absorção ativa de íons é reduzida (Sutcliffe, 1962, citado por CLARK, 1981). Entretanto, CUNNINGHAM e NIELSEN (1965) encontraram maior concentração de cátions nas plantas desenvolvidas em condições de baixa intensidade luminosa do que naquelas cultivadas em período ensolarado.

\footnotetext{
1 Parte da tese de Doutorado do primeiro autor, parcialmente financiada pela Embrapa Gado de Leite.

2 Eng ${ }^{\circ}$. Agrônomo, DS, Extensionista Agropecuário II, EMATER-MG. E.mail: crtcastro@zipmail.com.br

3 Engo. Agrônomo, PhD, Professor titular, Departamento de Zootecnia, Universidade Federal de Viçosa, MG. E.mail: rgarcia@mail.ufv.br

4 Engo. Agrônoma, PhD, Pesquisadora Embrapa Gado de Leite. E.mail: mmcarval@cnpgl.embrapa.br

5 Técnico Especializado, Embrapa Gado de Leite.
} 
A luz estimula a absorção de H2PO4- na maioria das plantas (JESCHKE, 1976) e, segundo MAYLAND e GRUNES (1974), gramíneas cultivadas sob $75 \%$ de sombreamento sofreram redução em seus teores de fósforo. Todavia, a redução da luminosidade ambiente não alterou esses teores em Brachiaria decumbens, $B$. humidicola, $B$. miliformis (SMITH e WHITEMAN, 1983), Pennisetum clandestinum e Stenotaphrum secundatum (SAMARAKOON et al., 1990).

Já McEWEN e DIETZ (1965) e BELSKY (1992) observaram maior concentração de fósforo na massa forrageira de pastagens nativas sombreadas por espécies arbóreas, enquanto ERIKSEN e WHITNEY (1981) constataram a mesma tendência em Brachiaria brizantha e Panicum maximum. WOLTERS (1974) relatou um caso extremo em que houve elevação de $116 \%$ no teor desse nutriente em Uniola laxa e U. sessiliflora, quando cultivadas sob 92\% de redução da luminosidade ambiente.

De acordo com JESCHKE (1976), a luz estimula o influxo de $\mathrm{K}+$ na maioria das plantas, concordando com HUNT e BURNETT (1973), que constataram queda na absorção desse elemento por Lolium perenne em resposta ao decréscimo luminosidade ambiente.

Entretanto, SMITH e WHITEMAN (1983) não observaram alterações significativas nos teores de potássio da forragem obtida de diversas gramíneas cultivadas à sombra de coqueiros. Já MAYLAND e GRUNES (1974) e ERIKSEN e WHITNEY (1981) registraram incremento da concentração desse nutriente nas gramíneas Agropyron desertorum, Brachiaria miliiformis, Elymus cinereus e Panicum maximum cultivadas em ambiente sombreado. SAMARAKOON et al. (1990) e BELSKY (1992) também observaram maior teor de potássio na forragem de gramíneas desenvolvidas à sombra.

A absorção de $\mathrm{Ca}^{2+}$ não é estimulada pela luz na maioria das plantas (JESCHKE, 1976), daí SAMARAKOON et al. (1990) não terem constatado alterações de seus teores em Pennisetum clandestinum e Stenotaphrum secundatum cultivados sob luz plena e $50 \%$ de sombreamento.

No entanto, MAYLAND e GRUNES (1974), WOLTERS (1974) e ERIKSEN e WHITNEY (1981) observaram incrementos significativos nos teores de cálcio de diversas gramíneas cultivadas à sombra. Ainda, segundo McEWEN e DIETZ (1965) e BELSKY (1992), a massa forrageira de gramíneas obtida à sombra de espécies arbóreas possuía con- centração de cálcio significativamente superior àquela amostrada em áreas adjacentes não-sombreadas.

O magnésio, componente da molécula de clorofila, é essencial para as reações fotoquímicas e metabólicas das plantas, sendo também de grande importância para os ruminantes; sua deficiência ou baixa disponibilidade provoca desordem nutricional, denominada tetania.

MAYLAND e GRUNES (1974) verificaram que a redução da intensidade luminosa afetou significativamente os teores de magnésio em Agropyron desertorum e Elymus cinereus, havendo elevação nas plantas submetidas a $75 \%$ de sombreamento. ERIKSEN e WHITNEY (1981), trabalhando em semelhantes condições de luminosidade, também observaram incremento significativo da concentração desse nutriente em Brachiaria miliiformis e Panicum maximum. Já em Pennisetum clandestinum e Stenotaphrum secundatum, a redução da luminosidade ambiente em 50\% não afetou tais teores (SAMARAKOON et al., 1990).

A exploração de sistemas silvipastoris implica na escolha de espécies forrageiras ecológica, nutricional e economicamente apropriadas às finalidades desejadas. Entretanto, ainda são poucas as informações acerca de espécies tropicais passíveis de utilização em tais sistemas. Nesse sentido, os objetivos deste trabalho foram estudar o efeito de três níveis de sombreamento artificial sobre a composição mineral de seis espécies de gramíneas forrageiras tropicais tradicionalmente cultivadas pelos pecuaristas brasileiros.

\section{Material e Métodos}

O ensaio foi conduzido na Estação Experimental da Embrapa Gado de Leite, em Coronel Pacheco, MG, em Latossolo Vermelho-Amarelo de textura média. Os tratamentos consistiram de seis espécies de gramíneas forrageiras tropicais - Brachiaria brizantha (Hochst ex A. Rich.) Stapf cv. Marandu; B. decumbens Stapf; Melinis minutiflora Beauv; Andropogon gayanus Kunth var. bisquamulatus (Hoscht) Hack, cv. Planatina; Panicum maximum Jacq., cv. Vencedor; e Setaria sphacelata Stapf exMassey, cv. Kazungula - submetidas a três níveis de sombreamento $(0,30$ e $60 \%$ de sombra, respectivamente, luz plena, sombra moderada e sombra intensa), segundo o delineamento em blocos ao acaso, com parcelas subdivididas e quatro repetições. Foram adotadas parcelas retangulares (níveis de sombreamento)

Rev. bras. zootec., 30(6S):1959-1968, 2001 
de $12 \times 3 \mathrm{~m}$ e subparcelas (gramíneas) de $3 \times 2 \mathrm{~m}$, coletando-se dados apenas na área interna útil $(2 \times 1 \mathrm{~m})$ de cada subparcela.

As análises químicas de amostras de solo $(0-20 \mathrm{~cm}$ de profundidade) apresentaram os seguintes resultados: pH em água, 4,52; $\mathrm{P}$ (Mehlich) $5,03 \mathrm{mg} / \mathrm{dm}^{3}$; e cátions trocáveis em cmolc/ $/ \mathrm{dm}^{3}-\mathrm{Ca}, 0,64 ; \mathrm{Mg}, 0,39$; $\mathrm{K}, 0,68$; e Al, 0,91 .

A área foi preparada mecanicamente por meio de aração e gradagem; foi feita calagem, aplicando-se $2 \mathrm{t} /$ ha de calcário dolomítico (correspondente à metade da dose calculada pelo método do $\mathrm{Al}$ e $\mathrm{Ca}^{+} \mathrm{Mg}$ trocáveis) e adubação básica com P e K, sendo 500 kg/ha de superfosfato simples e $167 \mathrm{~kg} / \mathrm{ha}$ de cloreto de potássio. As gramíneas foram semeadas em novembro de 1992 e durante a sua fase de estabelecimento a ressemeadura foi feita sempre que necessária.

O sombreamento artificial foi obtido pela cobertura das parcelas com telas plásticas (sombrite) a 1,5 $\mathrm{m}$ de altura do solo, tendo sido imposto somente após o completo estabelecimento das forrageiras, quando se fez um corte geral de uniformização, a $10 \mathrm{~cm}$ do solo, em novembro de 1994. Nessa ocasião, foi realizada adubação de manutenção, aplicando-se, em cobertura, $200 \mathrm{~kg} / \mathrm{ha}$ de superfosfato simples e $100 \mathrm{~kg} / \mathrm{ha}$ de cloreto de potássio.

A cada oito semanas, a partir da imposição do sombreamento, as subparcelas foram ceifadas, totalizando três cortes $(20 / 01,17 / 03$ e 12/05/95). Por ocasião do $1^{\circ}$ e $3^{\circ}$ cortes, foram retiradas amostras equivalentes a $10 \%$ da produção, para se determinarem o teor e o conteúdo de matéria seca da porção gramínea; essa foi subdividida em frações de caules e folhas, submetidas à secagem, moídas, utilizando-se peneira com malha de $1,0 \mathrm{~mm}$ de abertura, em moinho tipo Willey, por 15 minutos. As amostras de cada uma das frações foram destinadas às análises químicas, determinando-se os teores médios de $\mathrm{P}, \mathrm{K}, \mathrm{Ca}$ e $\mathrm{Mg}$, conforme procedimentos descritos por SILVA (1990).

Os dados foram submetidos à análise de variância e o efeito do sombreamento, àtécnica depolinômiosortogonais.

\section{Resultados e Discussão}

\section{Fósforo}

O teor de fósforo, nas folhas e nos caules, foi significativamente afetado pelo sombreamento em todas as gramíneas estudadas. As folhas de M. minutiflora apresentaram os mais elevados teo- res de fósforo em todos os níveis de luminosidade, não diferindo significativamente de $S$. sphacelata sob sombreamento intenso; sob 30 e $60 \%$ de sombreamento, estes teores foram estatisticamente equivalentes nas duas espécies de Brachiaria, embora sob luz solar direta tenham apresentado maior valor na $B$. brizantha. As mais baixas concentrações de fósforo na fração folhosa foram encontradas em $A$. gayanus, não diferindo de $B$. decumbens e $S$. sphacelata, quando sob luz plena (Tabela 1). B. brizantha e $S$. sphacelata foram classificadas como possuindo os mais elevados teores de fósforo nos caules, não diferindo estatisticamente de $B$. decumbens e $M$. minutiflora à sombra moderada; as menores concentrações ocorreram em A. gayanus, sendo estatisticamente equivalentes a $P$. maximum sob $30 \%$ de sombreamento e a $B$. decumbens e $P$. maximum sob luminosidade plena.

Na Figura 1, verifica-se que os teores de fósforo nas folhas e nos caules das espécies estudadas ocorreram aproximadamente na mesma faixa, variando de 0,15 a $0,36 \%$. A fração folhosa das espécies em estudo apresentou concentração de fósforo crescente em resposta ao declínio da luminosidade, atingindo os maiores valores sob sombreamento intenso. Comportamento crescente semelhante foi observado em relação a esses teores nos caules; embora o nível de fósforo em $P$. maximum tenha sofrido decréscimo sob moderada redução da luminosidade, nos caules de todas as espécies os valores mais elevados também ocorreram à sombra intensa (Figura 1).

O incremento dos teores de fósforo nas frações das espécies estudadas concorda com os relatos de vários autores referentes aos níveis desse nutriente na massa forrageira de diferentes gramíneas cultivadas à sombra (BURTON et al., 1959; McEWEN e DIETZ, 1965; WOLTERS, 1974; e ERIKSEN e WHITNEY, 1981).

O cultivo de $A$. gayanus, $B$. brizantha, $B$. decumbens eP. maximum sob $60-70 \%$ de sombreamento, conferido por um bosque de Anadenanthera macrocarpa, resultou em maior concentração de fósforo na fração folhosa dessas gramíneas e CARVALHO et al. (1995) comentam que o mais elevado teor desse nutriente provavelmente se deve à menor produção de matéria seca pelas plantas sombreadas.

\section{Potássio}

Na fração folhosa, o teor de potássio foi significativamente influenciado pelo sombreamento em A. gayanus, B. brizantha, M.minutiflora e $P$. maximum, mostrando-se independente da intensidade luminosa em $B$. decumbens e $S$. sphacelata.

Rev. bras. zootec., 30(6S):1959-1968, 2001 

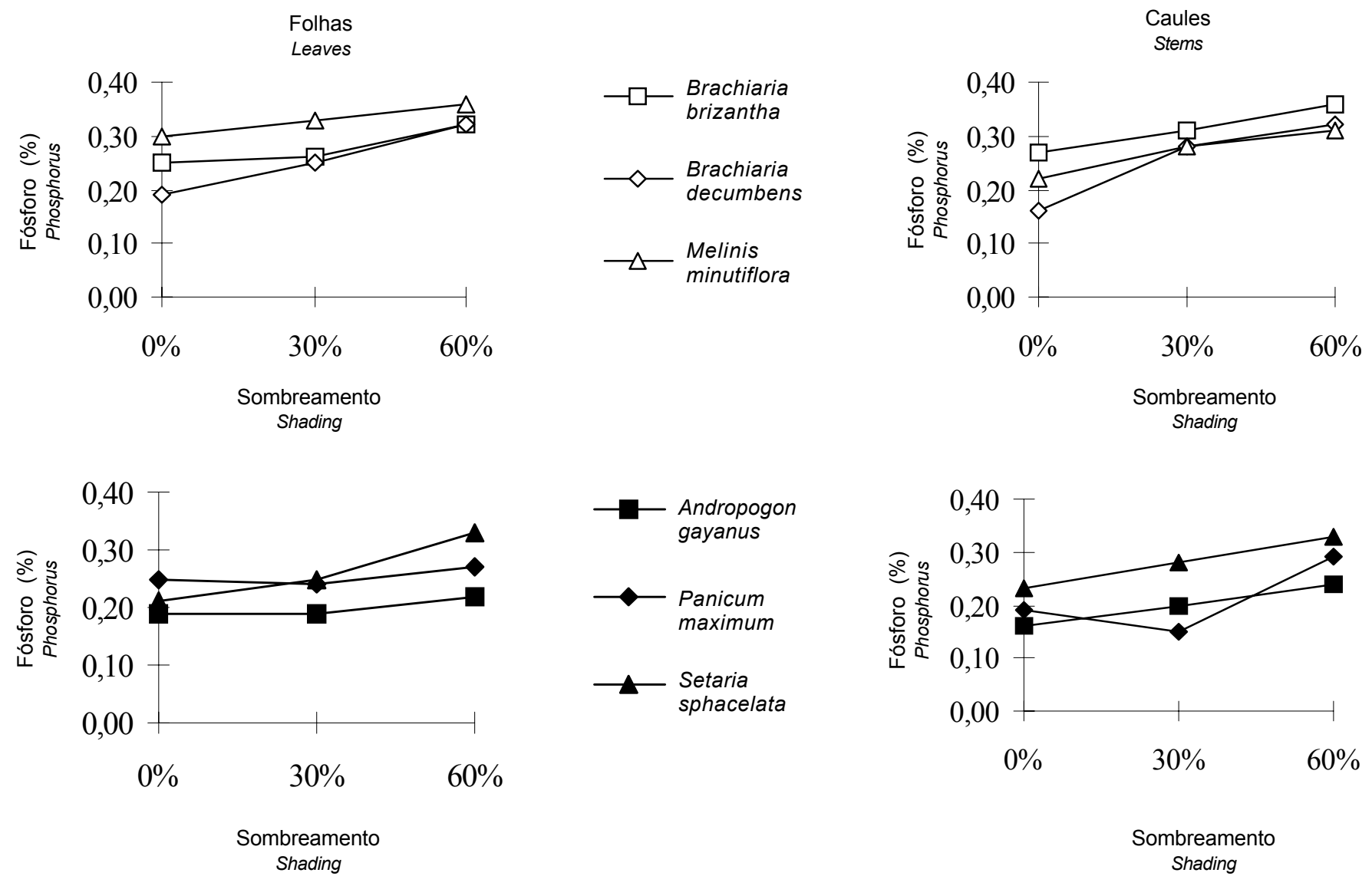

Figura 1 - Teores de fósforo nas folhas e nos caules de gramíneas cultivadas sob três níveis de sombreamento. Figure 1 - Phosphorus contents in leaves and stems of forages cultivated under three levels of shading.

Já nos caules, a concentração de potássio não foi significativamente afetada pela luminosidade ambiente apenas em $B$. decumbens.

A $S$. sphacelata foi uma das espécies que apresentou os mais elevados teores de potássio nas folhas, não diferindo de $B$. brizantha sob sombreamento de $60 \%$ e desta última e $B$. decumbens à sombra moderada; em todos os níveis de luminosidade estudados, os menores valores de potássio foram verificados em $A$. gayanus, sendo estatisticamente equivalentes à $M$. minutiflora sob luz plena e sob $30 \%$ de sombreamento (Tabela 1 ). Nos caules, a maior concentração de potássio sob luz plena e sombreamento moderado foi observada em S. sphacelata, não diferindo de $B$. decumbens e M. minutiflora nessa última condição, entretanto, sob $60 \%$ de decréscimo da luminosidade, o mais elevado teor desse elemento ocorreu em $P$. maximum. Em todos os níveis de sombreamento, a menor concentração do referido nutriente ocorreu em $A$. gayanus, não diferindo de $P$. maximum, quando cultivadas ao sol; as três espécies de porte baixo não diferiram entre si quanto aos teores de potássio nos caules quando sob intensa redução da luminosidade.

A Figura 2 revela que as concentrações de potássio nas folhas e nos caules variaram de 0,89 a 2,13\%, ocorrendo aproximadamente na mesma faixa. $\mathrm{O}$ teor de potássio na fração folhosa de A. gayanus, $B$. brizantha, $M$. minutiflora e $P$. maximum aumentou com o sombreamento progressivo e $B$. decumbens, a despeito da não-significância do efeito de sombreamento, apresentou a mesma tendência. Nos caules, comportamento semelhante foi observado em $B$. brizantha, M. minutiflora e P. maximum (Figura 2) e, em $B$. decumbens, embora a concentração de potássio não tenha sido significativamente influenciada pelo sombreamento, foi observada a mesma tendência; o teor desse nutriente em $A$. gayanus aumentou à sombra moderada, decrescendo com a sua intensificação, porém atingindo nível ainda superior àquele observado nas plantas cultivadas sob luz plena.

O comportamento de $S$. sphacelata referente

Rev. bras. zootec., 30(6S):1959-1968, 2001 
Tabela 1 - Teores (\%) de fósforo e potássio na matéria seca das folhas e dos caules de gramíneas cultivadas sob três níveis de sombreamento (médias de duas avaliações)

Table 1 - Phosphorus and potassium contents (\%) in the leaves and stem dry matter of forages cultivated under three levels of shading (mean of two evaluations)

\begin{tabular}{|c|c|c|c|c|c|}
\hline \multirow[t]{2}{*}{$\begin{array}{l}\text { Sombreamento (\%) } \\
\text { Shading }\end{array}$} & \multirow[t]{2}{*}{$\begin{array}{l}\text { Gramíneas } \\
\text { Forages }\end{array}$} & \multicolumn{2}{|c|}{$\begin{array}{c}\text { Fósforo }(\%) \\
\text { Phosphorus }\end{array}$} & \multicolumn{2}{|c|}{$\begin{array}{c}\text { Potássio (\%) } \\
\text { Potassium }\end{array}$} \\
\hline & & $\begin{array}{l}\text { Folhas } \\
\text { Leaves }\end{array}$ & $\begin{array}{l}\text { Caules } \\
\text { Stem }\end{array}$ & $\begin{array}{l}\text { Folhas } \\
\text { Leaves }\end{array}$ & $\begin{array}{c}\text { Caules } \\
\text { Stem }\end{array}$ \\
\hline 0 & $\begin{array}{l}\text { Brachiaria brizantha } \\
\text { Brachiaria decumbens } \\
\text { Melinis minutiflora } \\
\text { Andropogon gayanus } \\
\text { Panicum maximum } \\
\text { Setaria sphacelata }\end{array}$ & $\begin{array}{l}0,25^{\mathrm{bc}} \\
0,19^{\mathrm{d}} \\
0,30^{\mathrm{a}} \\
0,19^{\mathrm{d}} \\
0,25^{\mathrm{b}} \\
0,21^{\mathrm{cd}}\end{array}$ & $\begin{array}{l}0,27^{\mathrm{a}} \\
0,16^{\mathrm{c}} \\
0,22^{\mathrm{b}} \\
0,16^{\mathrm{c}} \\
0,19^{\mathrm{bc}} \\
0,23^{\mathrm{ab}}\end{array}$ & $\begin{array}{l}1,50^{\mathrm{b}} \\
1,59^{\mathrm{b}} \\
1,00^{\mathrm{cd}} \\
0,89^{\mathrm{d}} \\
1,18^{\mathrm{c}} \\
1,81^{\mathrm{a}}\end{array}$ & $\begin{array}{l}1,27^{\mathrm{c}} \\
1,56^{\mathrm{b}} \\
1,44^{\mathrm{b}} \\
1,09^{\mathrm{d}} \\
1,18^{\mathrm{cd}} \\
2,13^{\mathrm{a}}\end{array}$ \\
\hline 30 & $\begin{array}{l}\text { Brachiaria brizantha } \\
\text { Brachiaria decumbens } \\
\text { Melinis minutiflora } \\
\text { Andropogon gayanus } \\
\text { Panicum maximum } \\
\text { Setaria sphacelata }\end{array}$ & $\begin{array}{l}0,26^{\mathrm{b}} \\
0,25^{\mathrm{b}} \\
0,33^{\mathrm{a}} \\
0,19^{\mathrm{c}} \\
0,24^{\mathrm{b}} \\
0,25^{\mathrm{b}}\end{array}$ & $\begin{array}{l}0,31^{\mathrm{a}} \\
0,28^{\mathrm{a}} \\
0,28^{\mathrm{a}} \\
0,20^{\mathrm{b}} \\
0,15^{\mathrm{b}} \\
0,28^{\mathrm{a}}\end{array}$ & $\begin{array}{l}1,64^{\mathrm{a}} \\
1,61^{\mathrm{a}} \\
1,16^{\mathrm{bc}} \\
1,05^{\mathrm{c}} \\
1,25^{\mathrm{b}} \\
1,78^{\mathrm{a}}\end{array}$ & $\begin{array}{l}1,49^{\mathrm{b}} \\
1,61^{\mathrm{ab}} \\
1,70^{\mathrm{a}} \\
1,22^{\mathrm{c}} \\
1,52^{\mathrm{b}} \\
1,74^{\mathrm{a}}\end{array}$ \\
\hline 60 & $\begin{array}{l}\text { Brachiaria brizantha } \\
\text { Brachiaria decumbens } \\
\text { Melinis minutiflora } \\
\text { Andropogon gayanus } \\
\text { Panicum maximum } \\
\text { Setaria sphacelata }\end{array}$ & $\begin{array}{l}0,32^{\mathrm{b}} \\
0,32^{\mathrm{b}} \\
0,36^{\mathrm{a}} \\
0,22^{\mathrm{d}} \\
0,27^{\mathrm{c}} \\
0,33^{\mathrm{ab}}\end{array}$ & $\begin{array}{l}0,36^{\mathrm{a}} \\
0,32^{\mathrm{ab}} \\
0,31^{\mathrm{b}} \\
0,24^{\mathrm{c}} \\
0,29^{\mathrm{b}} \\
0,33^{\mathrm{ab}}\end{array}$ & $\begin{array}{l}1,92^{\mathrm{a}} \\
1,70^{\mathrm{bc}} \\
1,51^{\mathrm{c}} \\
1,05^{\mathrm{d}} \\
1,59^{\mathrm{bc}} \\
1,77^{\mathrm{ab}}\end{array}$ & $\begin{array}{l}1,68^{\mathrm{b}} \\
1,67^{\mathrm{b}} \\
1,70^{\mathrm{b}} \\
1,15^{\mathrm{d}} \\
2,10^{\mathrm{a}} \\
1,43^{\mathrm{c}}\end{array}$ \\
\hline
\end{tabular}

Em cada nível de sombreamento, médias seguidas de pelo menos uma mesma letra não diferem pelo teste de Tukey a $5 \%$ de probabilidade. In each shading level, means followed by the same letter do not differ by Tukey test at $5 \%$ of probability.

aos teores de potássio nas folhas e nos caules foi divergente daquele observado nas demais gramíneas, decrescendo em ambas as frações das plantas, embora de forma não-significativa na fração folhosa.

A crescente concentração de potássio em ambas frações das gramíneas estudadas, excetuando S. sphacelata, está de acordo com a maioria dos resultados contidos na literatura referentes aos níveis desse elemento na massa forrageira de diferentes espécies cultivadas sob luminosidade reduzida (MAYLAND e GRUNES, 1974; ERIKSEN e WHITNEY, 1981; e SAMARAKOON et al., 1990).

Segundo CARVALHO et al. (1995), os mais elevados teores de potássio nas folhas de A. gayanus, B. brizantha, B. decumbens, M. minutiflora e $P$. maximum, cultivadas à sombra, provavelmente se devem ao menor rendimento de matéria seca obtido nesta condição.

Todavia, HUNT e BURNETT (1973) detectaram declínio dos teores de potássio na massa forrageira de Lolium perenne resultante do seu cultivo sob luminosidade decrescente, afirmando que a taxa de absorção específica do referido ele- mento foi extremamente reduzida pela baixa intensidade de radiação no ambiente; tais resultados, embora conflitantes com o comportamento verificado nas demais gramíneas investigadas, vêm respaldar a tendência observada em $S$. sphacelata, espécie em que os níveis de potássio decresceram com a intensificação do sombreamento.

\section{Cálcio}

Houve efeito significativo da intensidade luminosa sobre os teores de cálcio nas folhas e nos caules de A. gayanus, B. brizantha, M. minutiflora, P. maximum e $S$. sphacelata. Em B. decumbens, o teor de cálcio revelou-se independente do sombreamento em ambas as frações das plantas.

Quando cultivadas sob sombreamento intenso as três espécies de porte alto possuíam os maiores teores de cálcio na fração folhosa, não diferindo estatisticamente entre si. À sombra moderada, a maior concentração ocorreu em $S$. sphacelata, não diferindo de $P$. maximum, quando se encontrava sob luz plena. Os menores níveis deste elemento foram constatados em $B$. decumbens, não diferindo signifi-

Rev. bras. zootec., 30(6S):1959-1968, 2001 

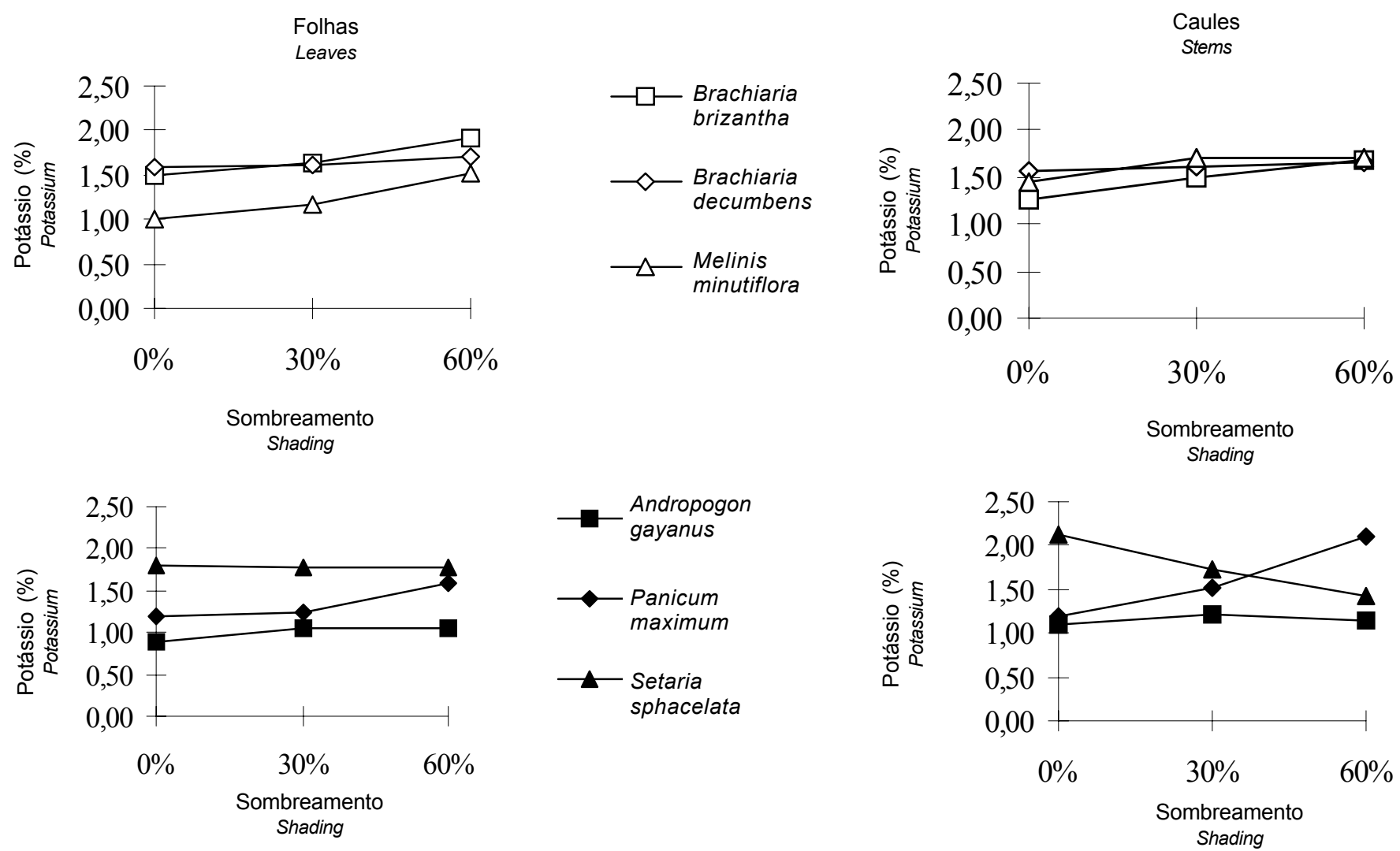

Figura 2 - Teores de potássio nas folhas e nos caules de gramíneas cultivadas sob três níveis de sombreamento. Figure 2 - Potassium contents in leaves and stems of forages cultivated under three levels of shading.

cativamente de $M$. minutiflora sob 30 e $60 \%$ de sombreamento (Tabela 2). Nos caules, a maior concentração de cálcio sob $60 \%$ de sombreamento ocorreu em P. maximum e, para a característica em questão, esta espécie apresentou valores estatisticamente equivalentes à $A$. gayanus, B. brizantha $\mathrm{e}$ $B$. decumbens, quando à sombra moderada, e à $A$. gayanus e $B$. decumbens, quando sob luz solar direta; os mais baixos teores de cálcio foram observados em S. sphacelata, não diferindo de M. minutiflora, à sombra moderada, e de A. gayanus, sob sombreamento intenso.

Nas gramíneas estudadas, os teores mais elevados de cálcio ocorreram nos caules, independente do nível de sombreamento, conforme se observa na Figura 3. Verifica-se também que o sombreamento resultou em sutil elevação dos teores de cálcio nas folhas de A. gayanus, B. brizantha, M. minutiflora, $P$. maximum e $S$. sphacelata; em $B$. decumbens, espécie em que a concentração de tal elemento não foi significativamente afetada pela intensidade luminosa, houve a mesma tendência.

O decréscimo da intensidade luminosa acarretou aumento da concentração de cálcio nos caules de M. minutiflora, P. maximum e S. sphacelata (Figura 3), havendo também ligeira elevação dos níveis desse nutriente em $B$. decumbens, a despeito da nãosignificância do sombreamento. Já em $B$. brizantha, apenas a sombra moderada acarretou elevação dos teores de cálcio, havendo, com a intensificação do sombreamento, pequeno decréscimo nestes valores. A concentração do referido elemento nos caules de A. gayanus apresentou variação destoante das demais gramíneas, mantendo-se constante à sombra moderada, sofrendo, porém, declínio com a posterior redução da luminosidade.

No presente estudo, a tendência geral dos teores de cálcio nas diferentes frações das plantas aponta para a sua elevação com o declínio da luminosidade, concordando com o exposto por vários autores em relação a esse nutriente na forragem obtida de gramíneas cultivadas à sombra (BURTON et al., 1959; McEWEN e DIETZ, 1965; MAYLAND e GRUNES, 1974; WOLTERS, 1974; e ERIKSEN e WHITNEY, 1981). Da mesma forma que B. brizantha, B. miliiformis, Digitaria decumbens,

Rev. bras. zootec., 30(6S):1959-1968, 2001 
Tabela 2 - Teores (\%) de cálcio e magnésio na matéria seca das folhas e dos caules de gramíneas cultivadas sob três níveis de sombreamento (médias de duas avaliações)

Table 2 - Calcium and magnesium contents (\%) in the leaves and stem dry matter of forages cultivated under three levels of shading (mean of two evaluations)

\begin{tabular}{|c|c|c|c|c|c|}
\hline \multirow[t]{2}{*}{$\begin{array}{l}\text { Sombreamento }(\%) \\
\text { Shading }\end{array}$} & \multirow[t]{2}{*}{$\begin{array}{l}\text { Gramíneas } \\
\text { Forages }\end{array}$} & \multicolumn{2}{|c|}{$\begin{array}{l}\text { Cálcio }(\%) \\
\text { Calcium }\end{array}$} & \multicolumn{2}{|c|}{$\begin{array}{c}\text { Magnésio (\%) } \\
\text { Magnesium }\end{array}$} \\
\hline & & $\begin{array}{l}\text { Folhas } \\
\text { Leaves }\end{array}$ & $\begin{array}{c}\text { Caules } \\
\text { Stem }\end{array}$ & $\begin{array}{l}\text { Folhas } \\
\text { Leaves }\end{array}$ & $\begin{array}{c}\text { Caules } \\
\text { Stem }\end{array}$ \\
\hline 1 & $\begin{array}{l}\text { Brachiaria brizantha } \\
\text { Brachiaria decumbens } \\
\text { Melinis minutiflora } \\
\text { Andropogon gayanus } \\
\text { Panicum maximum } \\
\text { Setaria sphacelata }\end{array}$ & $\begin{array}{l}0,29^{\mathrm{bc}} \\
0,25^{\mathrm{cd}} \\
0,23^{\mathrm{b}} \\
0,30^{\mathrm{b}} \\
0,36^{\mathrm{a}} \\
0,37^{\mathrm{a}}\end{array}$ & $\begin{array}{l}0,75^{\mathrm{b}} \\
0,87^{\mathrm{a}} \\
0,69^{\mathrm{b}} \\
0,89^{\mathrm{a}} \\
0,88^{\mathrm{a}} \\
0,59^{\mathrm{c}}\end{array}$ & $\begin{array}{l}0,10^{\mathrm{ab}} \\
0,12^{\mathrm{a}} \\
0,09^{\mathrm{abc}} \\
0,07^{\mathrm{c}} \\
0,11^{\mathrm{a}} \\
0,08^{\mathrm{bc}}\end{array}$ & $\begin{array}{l}0,08^{\mathrm{bc}} \\
0,09^{\mathrm{ab}} \\
0,09^{\mathrm{ab}} \\
0,07^{\mathrm{bc}} \\
0,12^{\mathrm{a}} \\
0,06^{\mathrm{c}}\end{array}$ \\
\hline 1 & $\begin{array}{l}\text { Brachiaria brizantha } \\
\text { Brachiaria decumbens } \\
\text { Melinis minutiflora } \\
\text { Andropogon gayanus } \\
\text { Panicum maximum } \\
\text { Setaria sphacelata }\end{array}$ & $\begin{array}{l}0,30^{\mathrm{cd}} \\
0,27^{\mathrm{de}} \\
0,23^{\mathrm{e}} \\
0,31^{\mathrm{c}} \\
0,37^{\mathrm{b}} \\
0,46^{\mathrm{a}}\end{array}$ & $\begin{array}{l}0,84^{\mathrm{a}} \\
0,87^{\mathrm{a}} \\
0,69^{\mathrm{b}} \\
0,89^{\mathrm{a}} \\
0,90^{\mathrm{a}} \\
0,66^{\mathrm{b}}\end{array}$ & $\begin{array}{l}0,13^{\mathrm{bc}} \\
0,19^{\mathrm{a}} \\
0,09^{\mathrm{d}} \\
0,12^{\mathrm{c}} \\
0,15^{\mathrm{b}} \\
0,09^{\mathrm{d}}\end{array}$ & $\begin{array}{l}0,11^{\mathrm{bc}} \\
0,13^{\mathrm{ab}} \\
0,09^{\mathrm{c}} \\
0,10^{\mathrm{c}} \\
0,15^{\mathrm{a}} \\
0,08^{\mathrm{c}}\end{array}$ \\
\hline 1 & $\begin{array}{l}\text { Brachiaria brizantha } \\
\text { Brachiaria decumbens } \\
\text { Melinis minutiflora } \\
\text { Andropogon gayanus } \\
\text { Panicum maximum } \\
\text { Setaria sphacelata }\end{array}$ & $\begin{array}{l}0,32^{\mathrm{b}} \\
0,27^{\mathrm{c}} \\
0,31^{\mathrm{bc}} \\
0,46^{\mathrm{a}} \\
0,49^{\mathrm{a}} \\
0,49^{\mathrm{a}}\end{array}$ & $\begin{array}{l}0,81^{\mathrm{b}} \\
0,88^{\mathrm{b}} \\
0,80^{\mathrm{bc}} \\
0,70^{\mathrm{d}} \\
1,03^{\mathrm{a}} \\
0,73^{\mathrm{cd}}\end{array}$ & $\begin{array}{l}0,24^{\mathrm{b}} \\
0,28^{\mathrm{a}} \\
0,09^{\mathrm{d}} \\
0,21^{\mathrm{c}} \\
0,21^{\mathrm{c}} \\
0,10^{\mathrm{d}}\end{array}$ & $\begin{array}{l}0,14^{\mathrm{b}} \\
0,18^{\mathrm{a}} \\
0,08^{\mathrm{c}} \\
0,15^{\mathrm{ab}} \\
0,16^{\mathrm{ab}} \\
0,09^{\mathrm{c}}\end{array}$ \\
\hline
\end{tabular}

Em cada nível de sombreamento, médias seguidas de pelo menos uma mesma letra não diferem pelo teste de Tukey a $5 \%$ de probabilidade. In each shading level, means followed by the same letter do not differ by Tukey test at $5 \%$ of probability.

P. maximum, Pennisetum clandestinum e $P$. purpureum, embora ERIKSEN e WHITNEY (1981) comentem que a elevação significativa dos teores de cálcio nessas últimas espécies tenha sido exacerbada na época fria, ocasião em que as plantas apresentaram menor taxa de crescimento.

Todavia, os resultados obtidos por SAMARAKOON et al. (1990) em ensaios com P. clandestinum e Stenotaphrum secundatum, nos quais não foram encontradas diferenças entre as concentrações de cálcio em plantas cultivadas à sombra e ao sol, são semelhantes aos observados, no presente ensaio, em relação à $B$. decumbens.

Magnésio

Os teores de magnésio nas folhas e nos caules de A. gayanus, B. brizantha, B. decumbens, $P$. maximum e $S$. sphacelata foram significativamente afetados pelo sombreamento. Em M.minutiflora, o efeito da luminosidade ambiente não foi significativo, tanto nos caules, quanto na fração folhosa.

Sob luz solar direta, os mais elevados teores de magnésio nas folhas foram observados nas espécies de porte baixo, não diferindo estatisticamente de $P$. maximum. Em todos os níveis de luminosidade, os maiores teores desse nutriente ocorreram em $B$. decumbens e sob luz plena a menor concentração foi constatada em A. gayanus, não diferindo de M. minutiflora e $S$. sphacelata; à sombra moderada ou intensa, essas duas últimas espécies também foram estatisticamente iguais e apresentaram os menores níveis do elemento (Tabela 2). Nos caules, $P$. maximum apresentou as mais elevadas concentrações de magnésio, independente da luminosidade, não diferindo de $B$. decumbens e $M$. minutiflora sob luz solar direta, de $B$. decumbens à sombra moderada e de $A$. gayanus e $B$. decumbens sob $60 \%$ de redução da intensidade luminosa. Os menores valores deste nutriente foram verificados em S. sphacelata, não diferindo de $M$. minutiflora, sob sombreamento intenso, A. gayanus e M. minutiflora, à sombra moderada, e $A$. gayanus e $B$. brizantha, sob luminosidade ambiente.

As folhas e os caules das espécies em estudo, com exceção de $M$. minutiflora, apresentaram con-

Rev. bras. zootec., 30(6S):1959-1968, 2001 

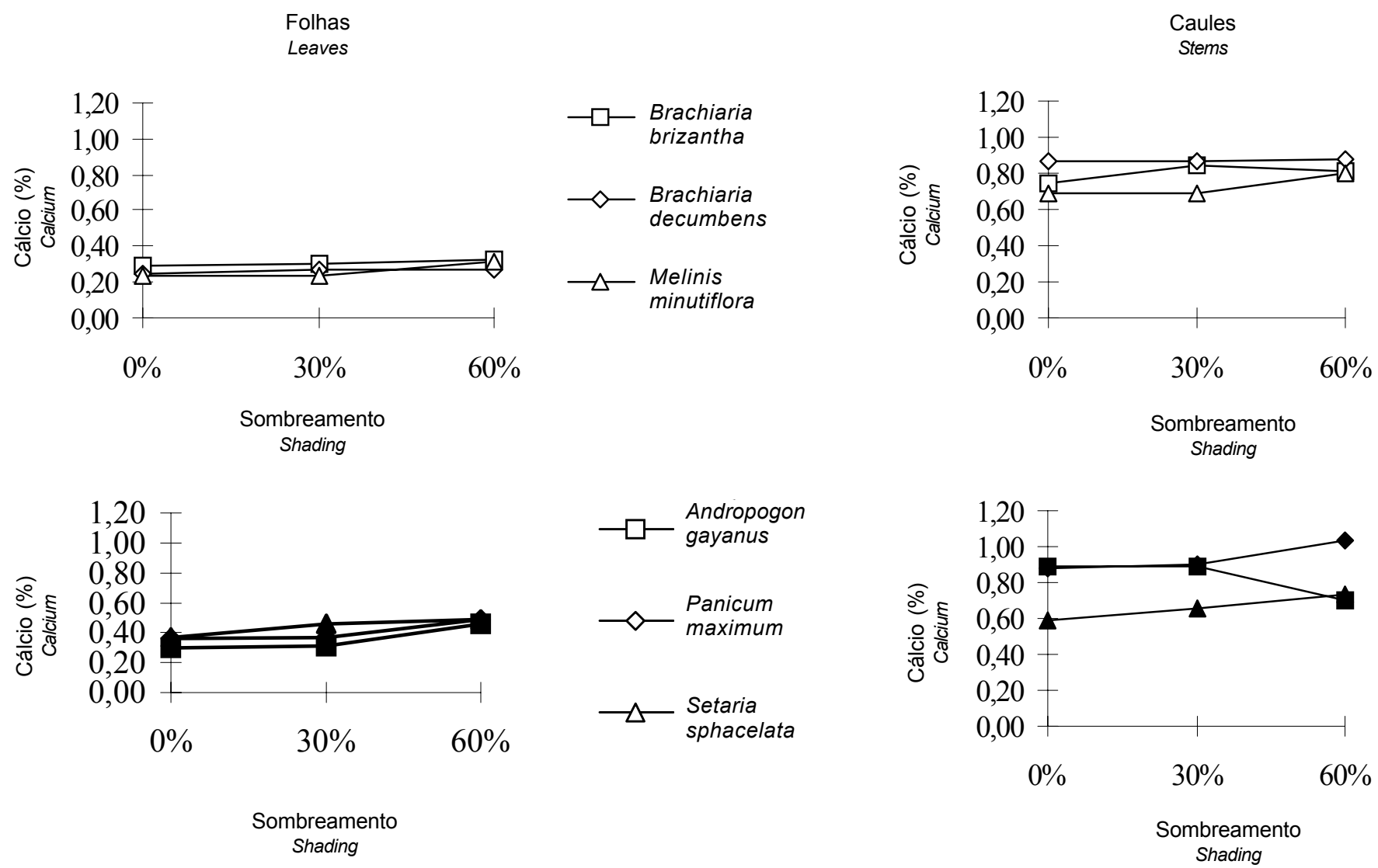

Figura 3 - Teores de cálcio nas folhas e nos caules de gramíneas cultivadas sob três níveis de sombreamento. Figure 3 - Calcium contents in leaves and stems of forages cultivated under three levels of shading.

centração de magnésio crescente em resposta ao sombreamento progressivo (Figura 4), embora a magnitude do aumento em $S$. sphacelata tenha sido bem inferior ao das demais. Os teores deste nutriente se mantiveram aproximadamente constantes em ambas as frações das plantas de M. minutiflora, estatisticamente indiferentes ao declínio da luminosidade ambiente.

Comparando os gráficos contidos na Figura 4, constata-se que, embora as maiores concentrações de magnésio tenham ocorrido sob sombreamento intenso em ambas as frações das plantas, estes valores foram bem mais elevados nas folhas, o que se deve à maior concentração de clorofila nas plantas sombreadas (HALE e ORCUTT, 1987), uma vez que o magnésio é um dos elementos que compõe a sua molécula e a intensidade luminosa afeta marcadamente as folhas, aparelho fotossintético por excelência (COOPER e TAINTON, 1968).

O incremento progressivo dos teores de magnésio na fração folhosa e nos caules de A. gayanus, $B$. brizantha, B. decumbens, $P$. maximum e S. sphacelata concorda com o perfil dessa característica observado na massa forrageira de diversas gramíneas cultivadas em condição de luminosidade reduzida (BURTON et al., 1959; MAYLAND e GRUNES, 1974; e ERIKSEN e WHITNEY, 1981). Já em $M$. Minutiflora, a indiferença dos níveis desse nutriente à intensidade luminosa encontra respaldo nos resultados obtidos por SAMARAKOON et al. (1990), em que a sua concentração em $P$. clandestinum e Stenotaphrum secundatum não foi afetada pelo sombreamento. 


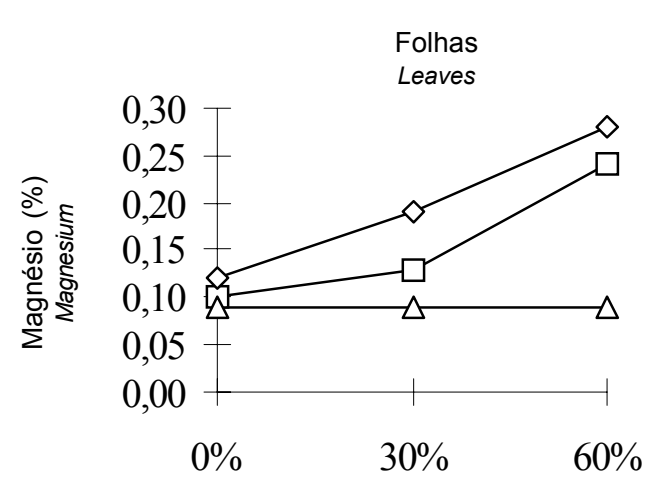

Sombreamento

Shading

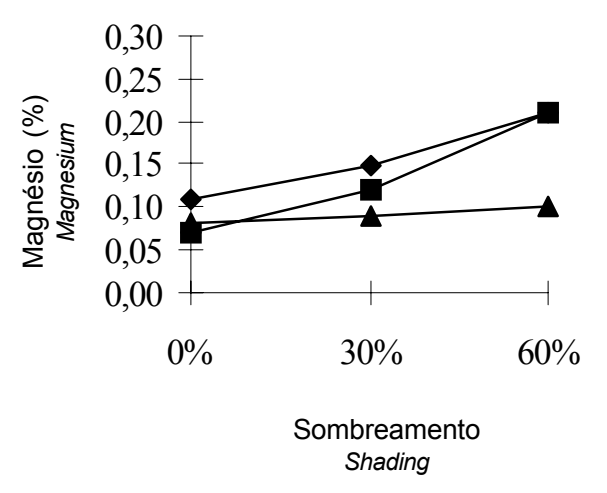

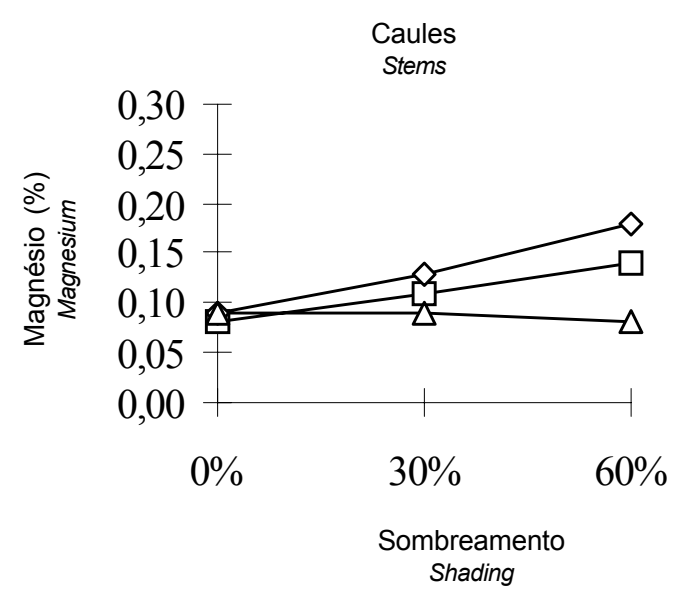
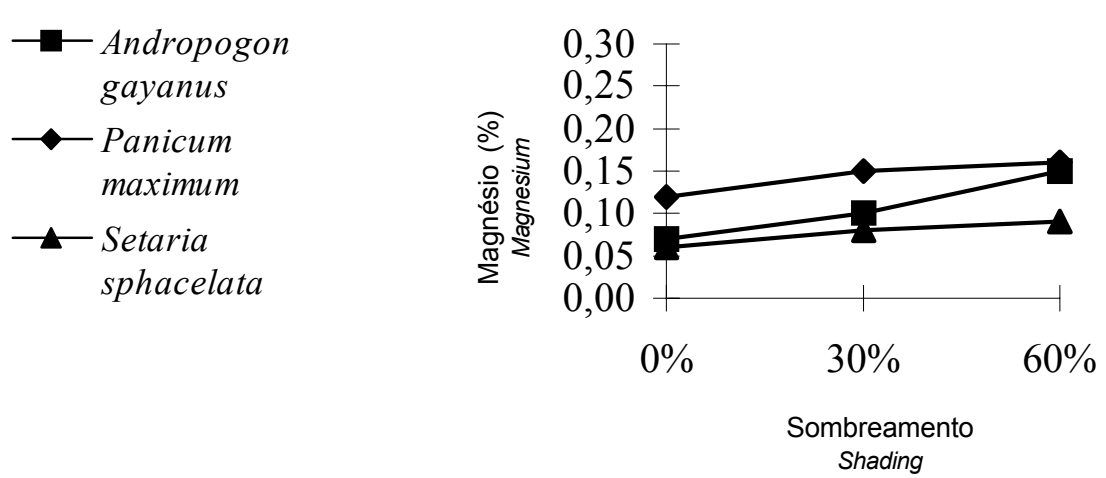

Figura 4 - Teores de magnésio nas folhas e nos caules de gramíneas cultivadas sob três níveis de sombreamento. Figure 4 - Magnesium contents in leaves and stems of forages cultivated under three levels of shading.

\section{Conclusões}

$\mathrm{O}$ sombreamento resultou em tendência geral à elevação dos teores de $\mathrm{P}, \mathrm{K}, \mathrm{Ca}$ e $\mathrm{Mg}$ na forragem das gramíneas estudadas, embora tenha promovido decréscimo significativo dos teores de $\mathrm{K}$ e Ca nos caules de S. sphacelata e A. gayanus, respectivamente.

\section{Referências Bibliográficas}

BELSKY, A.J. 1992. Effects of trees on nutritional quality of understore gramineous forage in tropical savannas. Trop. Grassl., 26(1):12-20.

BURTON, G.W., JACKSON, J.E., KNOX, F.E. 1959. The influence of light reduction upon the production, persistenceand chemical composition of coastal bermudagrass, Cynodon dactylon. Agron. J., 51(9):537-542.

CARVALHO, M.M., FREITAS, V.P., ANDRADE, A.C. 1995. Crescimento inicial de cinco gramíneas tropicais em um subbosque de angico-vermelho (Anadenanthera macrocarpa Benth.). Pasturas Tropicales, 17(1):24-30.

CLARK, R.B. 1981. Effect of light and water stress on mineral element composition of plants. J. Plant Nut., 3(5):853-885.

COMISSÃO DE FERTILIDADE DO SOLO DO ESTADO DE MINAS GERAIS - CFSEMG. 1989. Recomendações para o uso de corretivos e fertilizantes em Minas Gerais, $4^{\mathrm{a}}$ aproximação, Lavras. 176p.
COOPER, J.P., TAINTON, N.M. 1968. Light and temperature requirements for the growth of tropical and temperate grasses. Herbage Abstracts, 38(2):167-176.

CUNNINGHAM, R.K., NIELSEN, K.F. 1965. Cation-anion relationships in crop nutrition. V. The effects of soil temperature, light intensity and soil-water tension. J. Agric. Sci., 64(3):379-386.

ERIKSEN, F.I., WHITNEY, A.S. 1981. Effects of light intensity on growth of some tropical forage species. I. Interaction of light intensity and nitrogen fertilization on six forage grasses. Agronomy J., 73(3):427-433.

HALE, M.G., ORCUTT, D.M. 1987. The physiology of plants under stress. New York: John Willey \& Sons.

HUNT, R., BURNETT, J.A. 1973. The effects of light intensity and external potassium level on root/shoot ratio and rates of potassium uptake in perennial ryegrass (Lolium perenne L.). Annals of Botany, 37(151):519-537.

JESCHKE, W.D. 1976. Ionic relations of leaf cells. In: LÜTTGE, U., PITMAN, M.G. (Eds.) Transport in plants II, Part B, Tissues and organs. Encyclopedia of Plant Physiology, New Series, Springer-Verlag, New York. v.2, p.160-194.

MAYLAND, H.F., GRUNES, D.L. 1974. Shade-induced grass tetany prone chemical changes in Agropyron desertorum and Elymus cinereus. J. Range Manag., 27(3):189-201.

McEWEN, L.C., DIETZ, D.R. 1965. Shade effects on chemical composition of herbage in the Black Hills. J. Range Manag., 18(4):184-190.

RAVEN, J.A. 1969. Action spectra for photosynthesis and light

Rev. bras. zootec., 30(6S):1959-1968, 2001 
stimulated ion transport processes in Hydrodictyon africanum. New Phytologist, 68(1):45-62.

SAMARAKOON, S.P., SHELTON, H.M., WILSON, J.R. 1990. Voluntary feed intake by sheep and digestibility of shaded Stenotaphrum secundatum and Pennisetum clandestinum herbage. J. Agric. Sci., 114(2):143-150.

SILVA, D.J. 1990. Análise de alimentos: métodos químicos e biológicos. Viçosa, MG: UFV. 165p.

SMITH, F.A. 1968. Metabolic effects on ion fluxes in Tolypella intricata. J. Exp. Botany, 19(3):442-451.

SMITH, M.A., WHITEMAN, P.C. 1983. Evaluation of tropical grasses in increasing shade under coconut canopies. Exp. Agric., 19(2):153-161.

STRUIK, P.C. 1983. The effects of short and long shading, applied during different stages of growth, on the development, productivity and quality of forage maize (Zea mays L.). Netherlands J. Agric. Sci., 31(2):101-124.

TORRES, F. 1982. Role of woody perennials in animal agroforestry. Agroforestry Systems, 1(2):131-163.
WOLTERS, G.L. 1974. Longleaf uniola and spike uniola require shade. J. Range Manag., 27(1):45-47.

WONG, C.C, STÜR, W.W. Persistence of an erect and a prostate Paspalum species as affected by shade and defoliation. In: INTERNATIONAL GRASSLAND CONGRESS, 18, NICE, 1993. Proceedings ... Nice, 1993. p.2059-2060.

WONG, C.C., WILSOM, J.R. 1980. Effects of shading on the growth and nitrogen content of green panic and siratro in pure and mixed swards defoliated at two frequencies. Austr. J. Agric. Res., 31(3):269-285.

Recebido em: 17/04/00

Aceito em: 27/06/01 